\title{
Internationalization at the University of São Paulo
}

\author{
Raul Machado Neto
}

$\mathrm{T}$ he University of São Paulo, founded in 1934, started under the influence of important foreigners academicians in our campuses. The beginning of our university was the result of a fusion of the already existing colleges - Law School, School of Engineering, School of Pharmacy and Dentistry, College of Agriculture, Medical School, and School of Veterinary Medicine. In addition, in 1934, the School of Philosophy, Sciences and Letters was created being responsible for human sciences - Philosophy, History, Geography, Sociology - and hard sciences - Mathematics, Physics, and Chemistry - that academically amalgamated the professional existing colleges. In the thirties, we benefited from the instabilities in Europe and important professors came to the University of São Paulo contributing remarkably to our successful trajectory.

USP Medical School - "Faculdade de Medicina de São Paulo" - celebrated one hundred years of existence in 2013 and it has to be proud as a leading institution in the country. It owes much to Rockefeller Foundation that, in the first half of the century, was crucial to stablish the outstanding facilities for FMUSP.

Progressively, the vibrant American university system of teaching and research has influenced USP. Today, investigators from US universities are the most important contributors of our bulk of publication; about $44 \%$ of the papers published by USP professors are done in collaboration with them, being health the area with the largest production.

In 2016, with more than 1200 active agreements, with 750 institutions from 65 countries, the University of São Paulo plays an important role in the world academic scenario. Considering the institutions from 18 countries with which we have the most relevant scientific production, $45 \%$ of them are classified in the top 20 positions in their countries, according to the most prestigious rankings.

Ranked as the most important university among Iberoamerican countries, we are working in several ways to consolidate an international academic environment "at USP".

Double degrees, institutional initiatives with privileged partners, capacitation of our students in English proficiency and stimulus to enhance the number of courses given in English are part of our primary strategies. Additionally, two other important strategic actions are in place, to increase our presence in Latin America and to receive at our campuses a physical presence of international institutions. Related to Latin America, we created in 2014, the Latin American Academic Alliance, with Universidad Nacional Autónoma de México (UNAM) and Universidad

Provost for International Cooperation University of São Paulo.

Mailing address: Agência USP de Cooperação Acadêmica Nacional e Internacional / USP International Office. Universidade de São Paulo - USP. Av. Prof. Lúcio Martins Rodrigues, s/n, travessa 4 - Bloco B - $4^{\circ}$ andar. São Paulo/SP - Brasil. CEP: 05508-020. Webpage: www.usp.br/internationaloffice 
de Buenos Aires (UBA), with whom we already have several initiatives underway. Agreements were established with Paraguay, Chile, Ecuador and Colombia and we are already collaborating in the areas of health, engineering and agriculture. The presence of international institutions at USP consists of ongoing agreements with four privileged partner institutions which have reciprocal representative faculty. At this moment, representatives from University of Tsukuba and Université Sorbonne Paris Cité are at USP. Last year, we signed a historical tripartite agreement between Institut Pasteur, Oswald Cruz Foundation and USP, that includes a joint laboratory, USP-Institut Pasteur, which is under construction in our campus. Similar initiatives are being discussed with Rutgers University and The Ohio State University, as well as with Max Planck Institute of Germany.

The objectives that guide us today are the consolidation of a plural and highly qualified academic environment, without borders, at the University of São Paulo. 